\title{
A FORMAÇÃO DE PROFESSORES NO PARANÁ NA PRIMEIRA REPÚBLICA: \\ A ESCOLA NORMAL PRIMÁRIA DE PONTA GROSSA
}

\author{
THE FORMATION OF TEACHERS IN PARANÁ IN THE FIRST REPUBLIC: THE \\ NORMAL PRIMARY SCHOOL OF PONTA GROSSA
}

Vera Lucia Martiniak ${ }^{1}$

\begin{abstract}
RESUMO: Este trabalho apresenta resultados de pesquisa sobre a institucionalização da Escola Normal no Paraná, no período que compreende a proclamação da República até a década de 1930. Buscou-se analisar as imbricações que deram origem à Escola Normal do Brasil, como fator primordial para justificar a formação de professores no país. Na estrutura burocrática e hierárquica da Escola Normal conviveram os princípios da racionalização que objetivavam a eficácia e a eficiência, sendo que os recursos empregados deveriam ser utilizados de forma econômica. A investigação baseou-se em análises de fontes, tanto primárias quanto secundárias, que possibilitaram a reconstrução da estrutura organizacional da Escola Normal bem como a possibilidade de disponibilizar fragmentos do cotidiano da instituição. Por meio das leis referentes à instrução pública, procurou-se entender como tais regulamentações representaram os princípios do Estado para com a educação paranaense e de que forma legitimaram a criação da Escola. Os resultados demonstram que o Estado do Paraná não se diferenciava dos outros Estados, do ponto de vista ideológico, quando assumiu no seu discurso os ideais liberais: gratuidade, liberdade de ensino, obrigatoriedade, ênfase no caráter nacionalista, entre outros. A Escola Normal teve sua trajetória marcada por leis e decretos, mas conseguiu manter-se como instituição formadora de professores. A partir do momento de sua criação, outras foram sendo criadas, acentuando-se seu crescimento no período republicano. Essas escolas surgiram no momento em que o país passava por uma transição política e a difusão dos ideais liberais ressaltava a educação como instrumento de consolidação do novo regime e manutenção da ordem social.
\end{abstract}

Palavras-chave: Formação de professores. Escola Normal. Legislação educacional.

ABSTRACT: This paper presents research results on the institutionalization of the Normal School in Paraná, during the period that included the proclamation of the Republic until the 1930s. We have tried to analyze the imbrications that originated the Normal School of Brazil, as a prime factor to justify the teacher training in the country. In the bureaucratic and hierarchical structure of the Normal School, the principles of rationalization aimed at efficiency and effectiveness, and the resources

\footnotetext{
1 Professora permanente do Programa de Pós-Graduação em Educação da UEPG na linha de História e Políticas Educacionais e pesquisadora do Grupo de Estudos e Pesquisas História Sociedade e Educação-HISTEDBR da Universidade Estadual de Campinas. Doutora em Educação pela Universidade Estadual de Campinas.
} 
used should be used economically. The research was based on analysis of sources, both primary and secondary, that allowed the reconstruction of the organizational structure of the Normal School as well as the possibility of providing fragments of the institution's daily life. Through the laws regarding public education, we sought to understand how such regulations represented the State's principles for Parana's education and how they legitimized the creation of the School. The results show that the State of Paraná was not different from other states regarding the ideological point of view when it assumed in its discourse the liberal ideals: gratuity, freedom of education, compulsory requirement, emphasis on the nationalist character, among others. The Normal School's trajectory was marked by laws and decrees, but it managed to remain as a teacher-training institution. From the moment of its creation, others were being created, accentuating its growth in the republican period. These schools emerged as the country underwent a political transition and the diffusion of liberal ideals emphasized education as an instrument of consolidation of the new regime and maintenance of social order.

Keywords: Teacher training. Normal School. Educational legislation.

\section{Introdução}

Este estudo apresenta os resultados de pesquisa da dissertação de mestrado desenvolvida junto ao PPGE da Universidade Estadual de Ponta Grossa, da linha de pesquisa História e Políticas Educacionais, que buscou analisar a formação de professores no Paraná, no período que compreende a Primeira República.

As sucessivas reformas implementadas no período republicano refletiram-se em tentativas para reorganização do ensino por meio dos inúmeros decretos e regulamentos aprovados. Pode-se vislumbrar um ímpeto de renovação na instrução pública, considerando-se os interesses da sociedade dominante e suas conviç̧ões políticas e filosóficas. A expansão da rede escolar esbarrou, a princípio, na falta de elementos habilitados para exercer o magistério e, para solucionar o problema o Inspetor Geral do Ensino, Cesar Prieto Martinez, sugeriu a criação de duas escolas normais, uma em Ponta Grossa e outra em Paranaguá. A primeira, situada num grande centro considerado povoado e a outra atenderia a juventude de toda a faixa litorânea (PARANÁ, 1920).

Com a criação da Escola Normal Primária em Ponta Grossa (1924) e em Paranaguá (1927), o Estado passou a contar com três instituições 
encarregadas de formar professores; porém, o contingente de pessoas analfabetas ainda continuava grande. Com a aprovação do Regulamento das Escolas Normais Primárias de 1924, em substituição às determinações do Código de Ensino de 1917, percebeu-se, claramente, a concepção racionalizadora que se apresentou na reforma empreendida. Na estrutura burocrática e hierárquica da Escola Normal conviveram os princípios da racionalização que objetivavam a eficácia e a eficiência, sendo que os recursos empregados deviam ser utilizados de forma econômica.

Esse estudo buscou analisar a criação da Escola Normal, bem como seus objetivos e fins na formação do professor. Tomar a Escola Normal como ponto de partida não implica assumir uma atitude saudosista, mas procurar compreender a trajetória dessa instituição que se constituiu, inicialmente, como único curso de formação de professores, até a implantação do curso de Pedagogia no Brasil. Com essa postura, não se pretende tentar simplesmente justificar o presente pelos acontecimentos ocorridos no passado, pois isso seria um erro grosseiro, mas manter um "diálogo" com os fatos históricos e, assim, enriquecer as informações existentes sobre a formação do professor e, em especial, na região dos Campos Gerais (LUPORINI, 1994).

Procurou-se com o estudo, compreender como se deu o processo de formação de professores nos Campos Gerais - PR, a partir da institucionalização da Escola Normal norteada pelos interesses da classe dominante.

Nessa investigação a abordagem se deu por via da pesquisa qualitativa, com utilização da pesquisa bibliográfica e, concomitantemente, do uso combinado das fontes primárias. Compreendendo a importância das fontes primárias, procurou-se manter a fidedignidade da linguagem do período estudado.

Para o desenvolvimento do estudo foram cotejadas as fontes primárias e secundárias arroladas da seguinte forma: relatórios dos Secretários da Instrução Pública, mensagens dos governadores, Código de Ensino de 1917 e o Regulamento das Escolas Normais Primárias de 1924. As fontes secundárias utilizadas na pesquisa foram livros e artigos de 
historiadores que desenvolvem estudos sobre a história regional e, especialmente, sobre a temática estudada.

A utilização das fontes, tanto primárias quanto secundárias, foi imprescindível porque possibilitou a reconstrução da estrutura organizacional da Escola Normal, bem como a possibilidade de disponibilizar fragmentos do cotidiano da instituição. Portanto, por meio das leis referentes à instrução pública, procurou-se entender como tais regulamentações representaram os princípios do Estado para com a educação paranaense e de que forma legitimaram a criação da Escola Normal de Ponta Grossa.

A utilização das fontes documentais oficiais, como relatórios, pareceres, código de ensino e regulamentos, confirmam a centralidade do Estado. Por isso, pode-se afirmar que, na História da Educação Brasileira, o Estado tem sido o grande organizador da esfera educacional, o que justifica essa centralidade assim como o dualismo e o elitismo educacional.

Merece destaque o potencial contido nessas fontes, assim como a importância dos dados que se revelam para o pesquisador, os quais possibilitaram que informações anteriormente imersas viessem à tona, permitindo captar fragmentos da História da instituição, bem como da História regional e nacional.

Nessa perspectiva, revela-se o papel do historiador, pois, enquanto pesquisador, necessita estar preparado para articular as informações coletadas e, assim, reconstruir, sob o seu olhar, a História da instituição e dos seus atores.

A utilização das fontes primárias permitiu o deslocamento do olhar do pesquisador para a amplitude de informações que contribuíram para a análise e compreensão da temática abordada. O trabalho com essas fontes possibilitou reescrever a História da Educação dos Campos Gerais, uma vez que, inseridas em determinados contextos, elas propiciaram a captação de novos significados, desvelando aspectos pertinentes à temática proposta. Desta maneira, considera-se que a realidade não existe desvinculada de seus pressupostos reais dentro de um contexto concreto, em condições materiais determinadas. 
O texto está estruturado da seguinte forma: na primeira parte apresenta-se a institucionalização da Escola Normal no Brasil e o processo de feminização do magistério. Posteriormente, discute-se a reconstrução histórica da Escola Normal na cidade de Ponta Grossa - PR, e as suas especificidades decorrentes das reformas empregadas no contexto republicano, a partir dos ideais liberais. Por fim, conclui-se que a escola, na sociedade capitalista, é controlada pelo Estado e, consequentemente, reproduz as desigualdades sociais.

\section{A institucionalização da Escola Normal no Brasil}

No período imperial têm-se duas fases importantes: a fase jesuítica e a vinda da família real portuguesa para o Brasil. No primeiro, a educação ficou a cargo dos religiosos, com a intenção de instruir e catequizar os índios e, mais tarde, os filhos dos gentios e cristãos. O segundo marco foi caracterizado com a vinda da família real e a tentativa de transformar a colônia em sede da corte. Para atender às necessidades da população, foram tomadas medidas que determinaram alterações na área educacional, tais como a criação de cursos superiores e bibliotecas.

Entretanto, tais medidas causaram poucas modificações na situação do ensino primário e secundário, uma vez que a preocupação era exclusivamente com os cursos superiores. Estes deveriam atender às necessidades do mercado de trabalho e, para seu desenvolvimento, necessitariam de profissionais qualificados. Nas escolas secundárias, que davam acesso a estes cursos, frequentados pela minoria latifundiária, ou da elite da Corte, a educação manteve uma tradição aristocrática, que vinha desde os tempos dos jesuítas.

Nesse período, teve início a formação assistemática de professores, como uma tentativa para organizar um sistema de instrução primária, com a nomeação de professores e a implantação do método mútuo ${ }^{\text {. Nele }}$

2 O ensino mútuo surgiu na Inglaterra, durante a Revolução Francesa, quando alguns adolescentes instruídos diretamente pelo mestre atuavam como auxiliares, ensinando outros adolescentes, supervisionando a sua conduta e administrando os materiais 
ocorreu, ainda, uma iniciativa de organização e normatização do exercício da profissão docente, mas foi com a criação da Escola Normal que teve início uma nova etapa nesse processo.

Com o Ato Adicional de 1834, as províncias adquiriram poderes legislativos, garantindo a elaboração do seu próprio regimento, desde que estivessem em consonância com as imposições do Estado. Foi neste clima de organização da administração da província do Rio de Janeiro, que Rodrigues Torres ${ }^{3}$ propôs a criação da Escola Normal.

A preocupação com a formação docente respondia aos interesses dos dirigentes fluminenses, cujo intuito era tornar o professor um agente do Estado, capaz de formar futuros homens e cidadãos civilizados e, assim, romper as "trevas" que caracterizavam o passado colonial.

Segundo Villela (1990, p. 119), "[...] a difusão das Luzes se tornava para aqueles dirigentes o complemento indispensável da ação coercitiva exercida pelo Estado e a instrução pública, pelo seu potencial organizativo e civilizatório, mereceria atenção especial". Foi a partir desta necessidade de instruir o povo e centralizar o poder da classe dirigente que surgiu a Escola Normal do Rio de Janeiro, em 1835.

A escola destinava-se aos pretendentes à carreira docente e aos professores que exerciam o magistério. Para frequentá-la, os candidatos deveriam atender a exigências mínimas, ou seja, ser cidadão brasileiro, maior de dezoito anos, com boa morigeração ${ }^{4}$, e saber ler e escrever. Quanto à primeira exigência, garantia o acesso dos brasileiros às instituições públicas; a segunda estabelecia a idade mínima para a habilitação de professor; a seguinte relacionava-se à moral, bons costumes e boa educação, e era condicionada ao aval de um juiz de paz. E a última exigência dependia da avaliação do diretor da Escola Normal, sendo que o

didáticos. Á difusão do método coube a Andrew Bell e Joseph Lancaster. Para aprofundamento do tema, consultar: MANACORDA, M. A. História da educação: da antiguidade aos nossos dias. São Paulo: Autores Associados, 1989.

3 Joaquim José Rodrigues Torres era presidente da Província do Rio de Janeiro. Coube a ele e a seu cunhado Paulino José Soares de Souza a ideia de organizar uma Escola Normal na Província.

4 Era considerado um candidato morigerado aquele que possuía bons costumes ou vida exemplar. 
candidato deveria ter habilidades suficientes para leitura e escrita. Contudo, a ênfase maior era dada à moralidade.

Além da moralidade, estava implícita a questão da religião, uma vez que fazia parte do currículo da Escola Normal. Aos poucos, essa exigência foi se efetivando e tornando-se clara, até que, em 1862, passou-se a exigir um atestado do pároco sobre a religião do candidato.

Como se não bastassem os requisitos citados para o ingresso na carreira do magistério, os alunos que não possuíam condições financeiras suficientes para frequentar a escola recebiam do Estado recursos para manterem-se nela. Com isso, firmou-se um compromisso mútuo entre o Estado e o aluno: este, em contrapartida, ficava obrigado a exercer o magistério depois de habilitado.

Na Província do Paraná, o governante entendia que as dificuldades da instrução pública eram decorrentes das grandes distâncias que os alunos necessitavam percorrer e problemas financeiros com que se deparavam as famílias. Para solucionar ambas as dificuldades, sugeriu-se a criação de asilos para educar a infância desvalida, obrigando-a, mais tarde, a dedicarse ao magistério.

Foi, portanto, no contexto histórico do século XIX que surgiram as primeiras Escolas Normais e teve início a formação de professores para o ensino primário. Fundou-se, em Niterói, a primeira Escola Normal (1835) e, na sequência, na Bahia (1842), em São Paulo (1847), no Rio Grande do Sul (1869) e no Paraná (1876). Algumas Escolas Normais funcionavam anexas aos liceus ${ }^{5}$, como foi o caso da província do Piauí; o que diferenciava os dois cursos era a introdução da cadeira de Pedagogia no currículo.

Nos estudos de Kulesza sobre a institucionalização da Escola Normal no Brasil, salienta-se que, ao analisar o "[...] conteúdo da cadeira de Pedagogia assim criada e a pouca ênfase dada à prática pedagógica, podese concluir que esse curso tinha por objetivo a formação de dirigentes para

\footnotetext{
5 O ensino ministrado nos Liceus, de caráter secundário, era essencialmente masculino e dedicado à preparação para o ingresso no ensino superior. Eles tinham como modelo o Colégio Pedro II no Rio de Janeiro. Os Liceus constituíram-se como referencial para o desenvolvimento do ensino normal, emprestando seus professores, suas instalações e seus regulamentos para as novas escolas que iam sendo criadas (KULESZA, 1998).
} 
o ensino público" (KULESZA, 1998, p. 66). Este objetivo distanciou as mulheres do magistério, ficando o curso reservado essencialmente aos homens.

Em São Paulo, a Escola Normal funcionou, inicialmente, com uma seção masculina anexa à Faculdade de Direito e uma seção feminina anexa ao Seminário da Glória. "Essa seção parece ter surgido como meio de encaminhar as internas do Seminário, mantidas por donativos públicos e particulares" (CAMPOS, 1990, p. 7). De acordo com os padrões morais da época, a moça que atingisse 18 anos e não fosse pedida em casamento ou empregada como doméstica nas casas de famílias de "bons costumes" deveria preencher as cadeiras vagas na seção feminina. Portanto, a função docente era considerada como um prolongamento da vida do lar.

Com todas essas dificuldades, além do pouco interesse pela carreira docente e evasão dos alunos, a Escola Normal de Niterói foi extinta em 1851. A criação das primeiras Escolas Normais não previu a presença de alunas; mais tarde, após a recriação das escolas foram feitas várias tentativas para colocar moças e rapazes em dias alternados ou em prédios separados. A medida mais drástica foi adotada pelo diretor da Escola Normal de Pernambuco, que mandou colocar um muro no meio da sala, à frente do professor, onde era permitido "[...] que ele desse aula simultaneamente a alunos e alunas, mas não permitindo, entretanto, que esses dois grupos se enxergassem"(VILLELA, 2000, p. 122).

Durante o funcionamento da Escola Normal, houve um aumento do acesso das mulheres ao magistério, pois, configurou-se para muitas candidatas como uma das únicas opções para prosseguimento dos estudos. Com isso, o magistério começou a configurar-se como profissão feminina por excelência, a partir da segunda metade do século XIX.

O magistério, pouco a pouco, foi consolidando-se como carreira feminina, e em muitos casos, a profissão docente era exercida paralelamente a outra, devido a sua má remuneração. Os homens, considerados como "chefes de família", buscavam outras profissões mais rentáveis e aqueles que permaneciam exercendo o magistério recebiam tratamento diferenciado em relação à carreira e à remuneração. O salário 
pouco compensador foi um fator que acarretou o afastamento dos homens da carreira docente.

A profissionalização feminina no magistério público partiu do entendimento de que a educação escolar era uma extensão da educação dada em casa. Portanto, a função de mãe na família era estendida à escola pela pessoa da professora; com isso, criava-se o círculo que permitiria a profissionalização do magistério feminino.

Nesse processo, o magistério consolidou-se não apenas numericamente como profissão feminina, mas também como forma respeitável e institucionalizada de emprego para as mulheres de classe média. Contudo, a predominância feminina aliou-se ao conceito de vocação, já que a mulher foi considerada naturalmente apta para o exercício do magistério. Segundo Bruschini e Amado (1988, p. 5),

[...] a influência de correntes de pensamento que consideravam a mulher, e somente ela, dotada biologicamente pela natureza com a capacidade de socializar as crianças, como parte de suas funções maternas, e considerando que o ensino de crianças, na escola elementar, era visto como extensão dessas atividades, o magistério primário, desde o século passado, começou a ser considerado profissão feminina por excelência.

A Escola Normal ampliou-se, gradativamente, no século XX. A ruptura com o regime monárquico e a implantação da República, bem como a vinda de imigrantes e a ascensão da burguesia industrial, foram algumas transformações no cenário nacional que influenciaram a estrutura educacional.

A primeira Constituição Republicana, no artigo 34, alínea 30, definiu que a União ficaria responsável em legislar sobre a organização municipal do Distrito Federal e o Ensino Superior, enquanto que a Escola Primária e a Escola Normal continuavam sob a alçada dos estados. De acordo com Fusari e Cortese (1989, p. 73), nas "[...] leis e outras determinações legais, a Escola Normal não aparece nem como uma escola secundária de orientação, nem como escola de formação profissional"; ela permaneceu como uma escola de formação geral, que possibilitou o exercício do magistério. 
No Estado de São Paulo, o médico Caetano de Campos, diretor da Escola Normal, iniciou a primeira reforma nessa escola, em 1892. Em tal reforma, o currículo foi ampliado, com a introdução das disciplinas de Escrituração Mercantil, Noções de Economia Política, Biologia ou Organização e Direção das Escolas; em contrapartida, foram eliminadas as disciplinas de Pedagogia e Metodologia. Não se admitia ainda a co-educação e as aulas continuavam a ser ministradas de forma adequada a cada sexo: para as alunas foram destinadas as disciplinas de Caligrafia, Economia e Prendas Domésticas, enquanto que os alunos estudavam Álgebra e Escrituração Mercantil.

Em relação à metodologia utilizada, Caetano de Campos "[...] chegou à conclusão de que os métodos intuitivos eram os melhores" (CAMPOS, 1990, p. 9), pois acreditava que a criança deveria ser acostumada a raciocinar por si, fazendo-a descobrir as verdades que lhe eram necessárias. A reforma de Caetano de Campos foi inovadora e pioneira para sua época, trazendo modificações sensíveis à Escola Normal. Após sua morte prematura, ainda no ano de 1891, outras reformas foram implantadas na tentativa de readequar esse nível de ensino. A Lei no 169, de 1893, aumentou a duração do curso para quatro séries e eliminou a distinção entre o curso preliminar e complementar; também introduziu os Exercícios Militares e a Educação Cívica, devido à influência positivista.

As primeiras reformas implementadas no período republicano, sob a influência de Caetano Campos, "[...] procuraram introduzir um novo espírito, alterando mais o método e as idéias subjacentes, do que a própria organização do ensino normal" (CAMPOS, 1990, p. 11).

As reformas implementadas no Estado de São Paulo, nos Cursos Normal e Primário, exerceram uma grande influência nos outros estados, que enviaram representantes para observar as modificações realizadas. Entre esses estados estava o Paraná, que também fez visitas para conhecer os métodos e materiais utilizados na escola paulista e, assim, tentar adequá-los à sua realidade.

Apesar das reformulações sucessivas no ensino normal, evidenciou-se a ausência de uma linha de continuidade e coerência entre as diversas 
propostas. No início do século XX, a política educacional brasileira ocupavase mais especificamente com o Ensino Superior do que com os outros graus de ensino. Portanto, continuou presente a diferenciação da educação destinada às elites, nos ginásios que encaminhavam para o curso superior e a educação destinada ao restante da população, em Escolas Complementares e Escolas Normais, as quais possibilitavam o exercício de uma atividade.

A ampliação da Escola Normal conformou-se com os projetos das oligarquias regionais, cujo objetivo era alfabetizar a população analfabeta e, assim, aumentar o contingente de eleitores. Para Nagle (1974, p. 218), o processo de expansão e as reformas implantadas no ensino primário provocaram

[...] mudanças correspondentes na escola normal, de tal maneira que a preocupação com a primeira não pode ser analisada independentemente da preocupação com a segunda; na realidade, ambas constituíam duas facetas de um mesmo problema, pois a nova natureza e as novas funções atribuídas à escola primária se firmariam se, além de outras condições, fosse alterado e aperfeiçoado o curso de formação de professores primários, considerado a pedra angular para o perfeito êxito da nova escola primária.

Por conseguinte, a responsabilidade atribuída à Escola Primária estimulou uma ampla discussão em torno da Escola Normal, pois esta deveria oportunizar condições para que o professor executasse a sua missão com competência e responsabilidade. A expansão quantitativa do ensino primário foi atribuída ao movimento "entusiasmo pela educação"; entretanto, a preocupação com as questões qualitativas e pedagógicas centrou-se no "otimismo pedagógico". Analisando esse período, Nagle (1974, p. 101) afirma que:

O entusiasmo pela educação e o otimismo pedagógico, que tão bem caracterizam a década dos anos vinte, começaram por ser, no decênio anterior, uma atitude que se desenvolveu nas correntes de idéias e movimentos políticos sociais e que consistia em atribuir importância cada vez maior ao tema da instrução, nos seus diversos níveis e tipos. É essa inclusão sistemática dos assuntos educacionais nos programas de diferentes organizações que dará origem àquilo que, na década dos vinte, está sendo denominado de entusiasmo pela educação e otimismo pedagógico. 
Com a Primeira Guerra Mundial, surgiram preocupações sociais e políticas quanto às reformas educacionais, repercutindo num período de grande agitação de ideias por movimentos políticos. Entre as reformas realizadas nesse período destacam-se a de Sampaio Dória (1920), em São Paulo; a de César Prieto Martinez ${ }^{6}$, no Paraná; a de Lourenço Filho (1924), no Ceará; a de Anísio Teixeira (1927), na Bahia; e a de Carneiro Leão, no Rio de Janeiro.

Na reforma paulista, procurou-se atribuir à estrutura do currículo da Escola Normal, uma natureza essencialmente profissional, embora se notasse certo "[...] desequilíbrio entre as matérias de formação geral e as matérias de formação técnica, desequilíbrio que favorece as disciplinas do primeiro tipo" (NAGLE, 1974, p. 220).

Já na reforma baiana, o destaque se deu pela inclusão, no currículo, do ensino da agricultura, estabelecendo-se um currículo diferenciado para a Escola Normal da Capital e para as Escolas Normais das cidades do interior.

No Distrito Federal e em Pernambuco, a Escola Normal passou a ter a duração de cinco anos, divididos num ciclo geral ou propedêutico de três anos e num ciclo especial ou profissional de dois anos. Na reforma pernambucana, o ciclo profissional foi constituído de matérias de natureza técnica, enquanto que no Distrito Federal os dois ciclos não foram nitidamente diferenciados. Entretanto, em ambas as reformas foram introduzidas disciplinas especializadas, como História da Educação e Sociologia. Também previu-se uma nova diferenciação no curso profissional de formação de professores: no Distrito Federal, houve a criação da Escola Normal Rural; e, em Pernambuco, a criação da Escola Normal Superior.

Na reforma cearense foi instituída uma Escola Modelo destinada aos exercícios de prática pedagógica, sendo introduzida inicialmente a leitura analítica e, depois, o cálculo concreto, o ensino simultâneo da leitura e da escrita, o desenho natural, a cartografia e a ginástica sueca.

\footnotetext{
6 É comum os autores se referirem à reforma paranaense como sendo empreendida por Lysimaco Ferreira da Costa em 1923, mas o Relatório de 1920 esclarece a presença de Martinez no Paraná. "Tive a honra de ser escolhido dentre inúmeros professores do meu Estado [...] com o fim especial de remodelar o apparelho escolar existente" (MARTINEZ, 1920 , p. 3). Essa questão também é apontada na obra de Miguel (1997).
} 
As reformas empreendidas nos Estados mencionados tiveram como ponto favorável o papel desempenhado pelas escolas-modelo ou escolas de aplicação, instituídas anexas às Escolas Normais, para a prática pedagógica dos futuros professores, e, a instituição de curso de férias, para o aperfeiçoamento contínuo dos professores em serviço (NAGLE, 1974). A criação de Gabinetes de Psicologia e Pedagogia Experimental, bibliotecas para professores e alunos, laboratórios e museus pedagógicos, "[...] representa outras tantas iniciativas, cujo objetivo é fornecer as melhores condições para que o ensino se torne 'vivo' e melhor se desenvolvam os aspectos teóricos e práticos da escola normal" (NAGLE, 1974, p. 225).

Contudo, as reformas apresentaram limitações, entre elas a teórica, que representou uma "[...] forma de transplante cultural e de pedagogismo, isto é, de interpretação do fenômeno educacional sem ter claro as verdadeiras relações que ele estabelece com o contexto do qual é parte" (RIBEIRO, 1986, p. 91). O fenômeno educacional a que o autor se refere foi concebido como isolado do contexto, acreditando-se que a educação seria um fator determinante na mudança social.

Essa concepção ingênua da realidade é o resultado da adesão dos educadores brasileiros ao movimento da Escola Nova, cujos ideais foram transplantados da Europa e dos Estados Unidos. O movimento escolanovista visava a um novo tipo de homem para a sociedade capitalista. Entretanto, esquecia-se o fato fundamental dessa sociedade, o qual, segundo Ribeiro (1986, p. 111-112), "[...] é o de estar ainda dividida em termos de condição humana entre os que detêm e os que não detêm os meios de produção, isto é, entre dominantes e dominados".

As questões educacionais indicadas inserem-se num contexto em que a agricultura de exportação não oferecia condições para o desenvolvimento econômico, político e social, e que a dependência da economia brasileira deveria ser rompida com a economia externa. A estimulação do setor industrial apareceu, então, como solução para os dois problemas. Entretanto, a situação desencadeou a insatisfação de alguns grupos ${ }^{7}$ da

\footnotetext{
7 Esses grupos eram compostos por cafeicultores descontentes com a política de valorização do café, pelo setor pecuarista do Rio Grande do Sul, pelas camadas médias lideradas pelos
} 
sociedade, que se uniram para tomar o poder e derrubar o Partido Republicano.

Nesse cenário, a falta de medidas imediatas do governo liderado por Getúlio Vargas foi responsável pelo descontentamento também dos educadores, que participaram do movimento de reformas da década de 20 . Mais tarde, em 1932, eles apresentaram um "Plano de Reconstrução Educacional", através do Manifesto dos Pioneiros da Escola Nova.

Esse documento ${ }^{8}$ pautava-se nos princípios de laicidade, da obrigatoriedade, da gratuidade, da universalização do ensino, além de denunciar o estado de inorgacidade do aparelho escolar. Para tanto, os educadores que o elaboraram propunham a:

IX - Reorganização da administração escolar e dos serviços técnicos de ensino, em todos os departamentos, de tal maneira que todos esses serviços possam ser:

a) executados com rapidez e eficiência, tendo em vista o máximo de resultado com o mínimo de despesa;

b) estudados, analisados e medidos cientificamente, e, portanto, rigorosamente controlados no seu resultado (AZEVEDO et al., 1932, p. 90).

A luta pela construção de um plano nacional de educação impôs-se diante de um quadro marcado pela ausência de políticas de organização nacional do sistema de ensino e, portanto, os fins da educação deveriam ser definidos em função das mudanças econômicas e sociais, contrapondo-se à educação tradicional e verbalista relacionada com os interesses da classe dominante.

Finalmente, a discussão em torno das reformas educacionais empreendidas nas primeiras décadas do século XX leva a concluir que

tenentes e pelas massas populares que completam o quadro denominado de "Aliança Liberal".

8 O documento foi lançado em 1932, no Rio de Janeiro e São Paulo. O manifesto é assinado por Fernando de Azevedo e traz no final um apêndice em que se encontram os dados biográficos dos 26 signatários que exerciam funções ligadas ao magistério. O grupo responsável pelo documento nada tinha de homogêneo, era formado por liberais elitistas, como Fernando de Azevedo e Lourenço Filho; liberais igualitaristas, como Anísio Teixeira; e simpatizantes do socialismo, como Paschoal Leme. O Manifesto pautou-se, em linhas gerais, pela defesa da escola pública obrigatória, laica e gratuita e pelos princípios pedagógicos renovados inspirados nas teorias de Dewey e Kilpatrick. O documento teve por objetivo imprimir uma direção firme ao movimento renovador, opondo-se ao empirismo das reformas parciais. 
nenhuma delas chegou a produzir mudanças radicais, devido à falta de preparo do país para mudanças condizentes com a realidade social.

\section{A formação de professores e a Escola Normal Primária de Ponta Grossa}

No início do regime republicano houve várias tentativas para organizar a instrução pública no Estado do Paraná, por meio de decretos e códigos de ensino. As reformas aconteceram, sucessivamente, após o Decreto de 1091, na tentativa de organizar o ensino, ditado pelas convicções políticas e filosóficas dos governantes. Em 1903, foi aprovado o Regimento Interno das Escolas Públicas do Estado do Paraná; em 1907, uma comissão formada por professores do Ginásio Paranaense organizou um projeto para a instrução pública, que acabou tornando-se o Regulamento da Instrução Pública do Estado do Paraná. Em 1915 foi aprovado o primeiro Código de Ensino do Estado do Paraná, num período de efervescência política devido à Primeira Guerra Mundial, que ainda não havia findado.

A instrução pública foi normatizada por meio do Código de Ensino de 1917; porém, anteriormente, já era percebido nos relatórios dos governadores o discurso em relação à preocupação com o ensino e as dificuldades existentes. Conforme a mensagem de 1892, do governador do Estado, a instrução pública não atendia aos objetivos propostos. Dentre as causas do insucesso, o governante responsabilizou os pais que negligenciavam a instrução dos filhos, a falta de escolas, a incapacidade dos professores e a ausência de fiscalização:

Ahi estão essas tantas leis e regulamentos testemunhando que desde que foi installada a ex-provincia, a assembléa legislativa, e a administração jamais deixaram de attender á este importante ramo do serviço publico.

Pode-se affirmar, entretanto, que grande parte da população não saber ler e escrever.

A incapacidade de muitos professores, a incuria dos chefes de familia, ausencia de fiscalisação e a falta de escolas em 
zonas do interior distantes de povoações, são as causas principaes do atrazo da instrucção.

O magistério, ainda mesmo rodeado de todas as garantias de estabilidade e de independencia, em quanto fôr mais um meio de vida do que um sacerdocio, não corresponderá aos intuitos da sua instituição.

Não basta que o professor seja versado nas materias que constituem o programma da escola, é necessario que a par disso, se esforce com dedicação para bem cumprir os seus deveres. Eis ahi a difficuldade. (PARANÁ, 1892, p. 16).

Portanto, dentre as causas do fracasso da instrução pública, a maior responsabilidade era atribuída ao professor. Desde a implantação do novo regime, a instrução figurou como bandeira, mas na prática não se efetivou como proposta de governo.

No Estado do Paraná a formação de professores iniciou-se com a criação da primeira Escola Normal, na segunda metade do século XIX. A concretização do ato formalizou-se no dia 31 de julho de 1876, com a união do Instituto Paranaense e a Escola Normal. Entretanto, o número de alunos matriculados na Escola Normal ainda era pequeno e a dificuldade financeira do Estado do Paraná agravou a situação precária do ensino secundário. Os professores que lecionavam na Escola Normal também lecionavam no Ginásio Paranaense, sem aumento de vencimentos.

Diante desse quadro de dificuldades, a Escola Normal paranaense, como as demais instituições do país, passou por períodos de ativação e desativação. A crise mais profunda foi em relação às matrículas de alunos, pois eram poucos os candidatos à carreira docente. Somente com a industrialização, a educação escolar tornou-se um instrumento de ascensão para a classe trabalhadora. Para atender a essa demanda, exigiu-se dos Cursos Normais uma formação mais adequada dos profissionais, o que resultou na reformulação e ampliação desses cursos.

O quadro docente da Escola Normal era predominantemente masculino; somente com a instalação da Universidade do Paraná, em 1912, esse quadro tornou-se majoritariamente feminino. Grande parte dos professores que atuava na Escola Normal deslocou-se para exercer a docência no Ensino Superior, o que estimulou o ingresso das mulheres no magistério paranaense. No Relatório de 1921, César Prieto Martinez relatou que não hesitou em trazer pessoas de outros estados para atuarem no 
Paraná, justificando "[...] que grande parte dos moços estudiosos e intelligentes que nos podiam prestar preciosa collaboração, fugiam do magisterio para procurar no commercio ou nas universidades um novo meio de vida"(MARTINEZ, 1921, p. 7).

Em 1920, Caetano Munhoz da Rocha, presidente do Estado, determinou a construção de um edifício destinado à Escola Normal de Curitiba. Terminada a construção do prédio foi procedida a transferência dessa unidade para a nova sede, inaugurada em 7 de setembro de 1922, separando-se, definitivamente, a Escola Normal do Ginásio Paranaense. O Curso Normal passou a atender sua clientela com estrutura e prédio próprio. Essa ampliação estendeu-se também para o interior do Estado, com a criação da Escola Normal Primária em Ponta Grossa e outra em Paranaguá.

As reformas estaduais, que ocorreram nas primeiras décadas do século $X X$, inseriram-se no processo de urbanização da sociedade, em que "[...] firmava-se também a fração da burguesia industrial, que protegia os movimentos renovadores nas letras e nas artes, na política e na educação"(MIGUEL, 1997, p. 16). Entre as associações culturais, em 1923 foi fundada, por um grupo de intelectuais, a Academia de Letras do Paraná; em 1929 um grupo de intelectuais ligados à Igreja fundou o Círculo de Estudos Bandeirantes, liderados pelo padre Luís Gonzaga Miele e apoiados por José Loureiro Ascenção Fernandes e José Farani Mansur Guérios (FRESSATO, 2003).

Nessas primeiras décadas, o ambiente cultural de Curitiba foi cenário de disputas entre o grupo ligado à Igreja e o grupo ligado aos republicanos. Foi esse contexto que, de certa forma, "[...] ajudou a definir o modo como a reforma educacional foi implantada na Escola Normal em 1923" (MIGUEL, 1997, p. 20). A autora também complementa com outros acontecimentos culturais que influenciaram as reformas no ensino paranaense, como a fundação da Universidade do Paraná, em 1912, e a presença de imigrantes nos movimentos operários.

A economia do Paraná, nesse período, passou por um processo de transformações estruturais que inauguraram uma nova etapa, em função da 
diminuição da atividade tropeira e do desenvolvimento da economia ervateira. Foi neste clima de transformações que o grupo ligado à ervamate começou a se organizar socialmente na luta por seus interesses e a exercer pressão em busca da participação política.

Foi por pressão das populações desta classe emergente que as escolas primárias se concretizaram, assim como fez pressão dos pais por melhores professores nas cidades mais importantes.

À medida que os núcleos se urbanizavam, o processo de urbanização criava na população a necessidade de outras formas de participação social que não aquelas do meio rural e a população reconhecia na escola, uma das mediações para se inserir, de modo satisfatório, nas novas relações de produção. (MIGUEL, 1997, p. 23-24).

A situação educacional no Paraná, como no restante do país, era precária. Até a primeira reforma implementada por Martinez, o ensino paranaense foi regulamentado pelo Código de Ensino de 1917. Segundo a legislação, os professores eram classificados conforme a sua escolaridade: normalistas e não normalistas (provisórios, efetivos, adjuntos e subvencionados), e somente poderiam ser nomeados para o cargo se comprovassem capacidade física e moral. Ou seja, não poderiam ter nenhuma moléstia contagiosa ou defeito físico que dificultasse o exercício do magistério, além de ter um comportamento exemplar, isento de crimes ou vícios. Se, no decorrer do exercício do magistério, o professor se tornasse moralmente incapaz, seria demitido do quadro de docentes.

A reforma empreendida no Paraná por César Prieto Martinez ${ }^{9}$, depois da realizada em São Paulo por Sampaio Dória, buscou a eficiência da Escola Normal e, em decorrência, a dos professores. Para tanto, foram reformulados os programas escolares e promoveu-se a fiscalização e adequação dos recursos, entre outras medidas. Além da reformulação da Escola Normal, essa reforma implicou a separação do Ginásio, "[...] pois sendo cursos diferentes, com objetivos e programas próprios, não haveria justificativa para que as aulas fossem ministradas juntas" (LUPORINI, 1994, p. 24-25). No Relatório de 1920, Martinez justificou a sua decisão:

${ }^{9}$ César Prieto Martinez foi convidado pelo Presidente da Província para exercer o cargo de Inspetor Geral do Ensino, que atualmente corresponde ao de Secretário da Educação, para remodelar o aparelho escolar. 
Uma das primeiras medidas postas em pratica logo após o inicio da minha gestão, foi a separação do curso da Escola Normal do Gimnasio.

Os lentes, acumulando as funcções de cathedraticos de ambos os estabelecimentos, passaram a receber uma gratificação de $150 \$ 000$ mensaes. Escusado é encarecer o grande alcance que disso resulta, pois sendo differente a missão de cada estabelecimento, com programma diverso, não se justificava que as aulas fossem dadas em conjuncto. (MARTINEZ, 1920, p. 15).

Quanto ao programa do curso, Martinez introduziu modificações na sua estrutura:

Os actuaes programmas exigem modificações, de accordo com as necessidades da Escola, principalmente os da cadeira de Pedagogia.

Foram extendidas ao $3^{\circ}$ e 40 anos, varias matérias, tendo-se em vista melhorar, tanto quanto possível, o preparo dos futuros professores.

O programma de Pedagogia passou, a titulo de experiência, por uma completa reforma e comprehende:

a) Anthropologia Pedagógica, no $2^{\circ}$ anno;

b) Psycologia Infantil apliccada à educação, no $3^{\circ}$ anno;

c) Methodologia Geral e Historia da Pedagogia, no $4^{\circ}$ anno. (MARTINEZ, 1920, p. 15).

$\mathrm{Na}$ análise dos relatórios sobre a instrução pública primária e secundária, elaborados pelo Inspetor Geral do Ensino, César Prieto Martinez, detectou-se a concepção racionalizadora da Educação, que buscava a eficiência da escola e de seus profissionais com poucos investimentos despendidos.

O Paraná já é um exemplo que deve ser seguindo. Sua organisação escolar prima pela simplicidade. Os gastos são rigorosamente fiscalisados e tem apliccação conveniente. As verbas para tal fim não são excedidas. Basta dizer que com o mesmo dinheiro despendido em 1916, custeamos o mesmo numero de esolas em 1921 e duplicamos a matricula (MARTINEZ, 1921, p. 13).

A racionalização do ensino estava inscrita no modelo de nacionalidade manifesto na Associação Brasileira de Educação e nas reformas renovadoras implementadas nos demais Estados. Os mecanismos de controle sociais corporificaram-se na organização escolar, na quantificação estatística dos dados e nas atividades disciplinares dos alunos (MIGUEL, 1997). A racionalização da Educação manifestou-se nos discursos pedagógicos a 
partir dos anos 20 do século $X X$, sendo que o termo tornou-se referência para diversos projetos que propunham novas formas de reorganizar a sociedade brasileira.

A formação de quadros para o magistério público ficou a cargo da Escola Normal de Curitiba, sendo que, em 1924, Martinez implantou mais duas escolas normais: uma em Paranaguá e outra em Ponta Grossa. Em 27 de fevereiro de 1924, foi inaugurada a Escola Normal Primária de Ponta Grossa, com o objetivo de absorver os alunos oriundos da Escola Intermediária que desejavam seguir o magistério. O curso intermediário compreendia dois anos e habilitava o aluno a matricular-se no primeiro ano da Escola Normal.

A Escola Normal possuía um currículo próprio e o seu corpo docente dividia-se em duas categorias: os catedráticos e os professores de segundo grupo. Os professores catedráticos, segundo o Regulamento das Escolas Normais Primárias, constituíam as seguintes cadeiras: Português e Literatura, Matemática, Ciências Físicas, Naturais e Higiene, Geografia e História, Pedagogia e Psicologia. Já os professores de segundo grupo constituíam as cadeiras de: Desenho, Música, Ginástica e Trabalhos Manuais. Os programas das disciplinas foram organizados pela Inspetoria Geral do Ensino, mas previa-se a sugestão do diretor e dos professores quanto à organização dos conteúdos, desde que estes fossem submetidos à aprovação do governo estadual. O Regulamento de 1924 determinou que as práticas pedagógicas fossem realizadas no Jardim de Infância, no Grupo Escolar e na Escola Isolada, porém não contemplou nenhuma disciplina metodológica que subsidiasse a prática do futuro professor.

O relatório de 1925-1926 descreve a fundação da escola, bem como sua estrutura administrativa e a constituição do corpo docente. Segundo o relatório, a escola era constituída de uma Escola de Aplicação, que contava com um curso complementar primário com duas classes, um grupo escolar ${ }^{10}$ com quinze classes, uma escola isolada com três classes e um jardim de infância com duas classes. Estas classes eram utilizadas para a prática

\footnotetext{
10 Segundo o Código de Ensino de 1917, duas ou mais escolas, que funcionassem na mesma localidade, com frequência média, poderiam se reunir para organizar um grupo escolar.
} 
pedagógica das normalistas. A escola contava ainda em seu corpo docente com: cinco lentes catedráticos, quatro professores do curso normal, dois professores do curso complementar, quinze professores do grupo escolar, um professor da escola isolada e dois professores do jardim de infância.

As aulas eram diárias, com duração de quatro horas, divididas em 45 minutos, com um intervalo de 10 minutos. Poderiam começar às 8 horas e encerrar ao meio dia, ou do meio dia às 16 horas, conforme a determinação do governo estadual. O ano letivo iniciava no dia primeiro de março e encerrava-se no dia catorze de novembro; no dia dezesseis do mesmo mês iniciava-se o exame final.

A escola ficou sob a direção do Dr. Joaquim Meneleu de Almeida Torres, também responsável pela Escola de Aplicação e Escola Complementar. A inspeção escolar foi realizada pelo professor Segismundo Antunes Netto e o Inspetor Geral desse período foi o professor Lysimaco Ferreira da Costa.

Conforme o Regulamento das Escolas Normais Primárias de 1924, as escolas normais deveriam conter em seu quadro administrativo: um diretor, um bibliotecário, um inspetor de alunos, um porteiro, um contínuo e cinco zeladoras (PARANÁ, 1924). Conforme o artigo 151 do Regulamento das Escolas Normais Primárias, o cargo de diretor seria ocupado pelo melhor professor normalista, havendo probabilidade de a escolha recair sobre um dos docentes do estabelecimento.

As competências conferidas ao cargo de diretor da Escola Normal foram descritas no capítulo $\mathrm{XV}$, que continha quatro artigos e vinte e três alíneas. De uma forma geral, competia ao diretor: a organização e a fiscalização do trabalho pedagógico, o disciplinamento e o cumprimento das ordens provenientes da Inspetoria Geral do Ensino. Não havia nenhuma referência quanto à questão da orientação pedagógica destinada aos professores. A relação entre direção e corpo docente ocorria verticalmente, entretanto, a direção escolar, juntamente com os professores, organizavam palestras pedagógicas.

Sob a orientação do seu reforçado director realizam os lentes e professores, semanalmente, as suas palestras pedagógicas, 
nas quaes fortificam e ampliam os seus conhecimentos profissionaes e criam novas fontes de estímulo para 0 exercício da ardua tarefa a seu cargo e para a elevação da sua própria cultura. (PARANÁ, 1925-1926, p. 462).

As palestras pedagógicas, inicialmente, eram preparadas pelos próprios professores, que dissertavam sobre um assunto escolhido. Quando Roberto Emílio Mongruel assumiu a direção, em 1927, procurou redimensionar as palestras com assuntos voltados para as disciplinas de Pedagogia e Metodologia.

Frisa-se que os princípios da Escola Nova estavam presentes nas reformas empreendidas nos Estados, sendo que as ideias renovadoras decorriam do "[...] desenvolvimento do capitalismo que, ao transformar o capital agrícola (gerado pela lavoura cafeeira) em capital industrial, tinha necessidade de funcionários e de trabalhadores mais qualificados ou, ao menos, alfabetizados."(MIGUEL, 1997, p. 17).

Nesse processo de industrialização, a preocupação com a manutenção da ordem e da disciplina, cobrada tanto dos alunos quanto dos professores, prevaleceu como eixo central do processo educacional, por parte dos governantes paranaenses. Neste sentido, o diretor assumiu um papel essencial na estrutura burocrática do estado, sendo considerado elemento de grande importância para o progresso e desenvolvimento da instrução pública. No interior da instituição de ensino, ele substituiria o governo estadual no exercício do controle e da fiscalização do trabalho docente. Portanto, para ocupar o cargo de diretor da Escola Normal, escolhia-se o melhor professor normalista em exercício, para ser nomeado pelo governo. Vale dizer ainda que, mais que a competência profissional exigida para o cargo, os interesses do diretor deveriam estar em consonância com os interesses do governo.

A implantação das Escolas Normais em Ponta Grossa e Paranaguá não aconteceu somente devido às condições favoráveis do Estado do Paraná, cuja economia baseava-se, predominantemente, na erva-mate e no crescimento do setor madeireiro, mas, principalmente, como orientação ideológica do regime republicano, interessado em democratizar o ensino, como forma de sedimentação e civilização do povo. 
A análise dos Relatórios de Martinez permitiu explicitar os propósitos das reformas no ensino: higienizar, civilizar e modernizar. Martinez propôs a criação do Serviço Médico-Escolar, "[...] considerando que prestaria inestimáveis serviços à saúde de alunos e professores, por meio de visitas periódicas" (LUPORINI, 1994, p. 27). A intencionalidade da reforma apresentou-se em um contexto de aumento demográfico, principalmente, com a vinda de imigrantes nas regiões menos povoadas e, consequentemente, com a necessidade de moradia e saneamento para população.

Por volta de 1930, com Getúlio Vargas na presidência da República, iniciou-se um período de desenvolvimento econômico pela via da industrialização, em que o aparelhamento escolar tentou se adequar aos rumos tomados pela economia nacional e pelas relações comerciais com outros países.

Nesse cenário, a Escola Normal novamente sofreu modificações em sua estrutura. O Curso Normal foi desdobrado em dois cursos: geral e especial. O curso geral, com duração de três; anos e o curso especial, com duração de dois anos. A escola passou a denominar-se Escola Normal Secundária de Ponta Grossa e o currículo constituiu-se das seguintes matérias:

Quadro 1 - Currículo da Escola Normal- curso geral

\begin{tabular}{|c|c|c|}
\hline $1^{\circ}$ Ano & 20 Ano & $3^{\circ}$ Ano \\
\hline $\begin{array}{l}\text { Português } \\
\text { Matemática } \\
\text { História Natural } \\
\text { Agronomia } \\
\text { Geografia Geral } \\
\text { Corografia do Brasil } \\
\text { Desenho } \\
\text { Música } \\
\text { Trabalhos de Agulha } \\
\text { Economia Doméstica } \\
\text { Trabalhos Manuais } \\
\text { Ginástica }\end{array}$ & $\begin{array}{l}\text { Português } \\
\text { História da Civilização } \\
\text { Matemática (Aritmética } \\
\text { Álgebra) } \\
\text { História Natural } \\
\text { Física } \\
\text { Francês } \\
\text { Desenho } \\
\text { Trabalhos de Agulha } \\
\text { Economia Doméstica } \\
\text { Música } \\
\text { Ginástica Manuais } \\
\text { Trabalhos Malo }\end{array}$ & $\begin{array}{l}\text { Literatura } \\
\text { História do Brasil, Moral e } \\
\text { Civismo } \\
\text { Matemática (Geometria) } \\
\text { Química e Higiene } \\
\text { Francês } \\
\text { Psicologia Geral } \\
\text { Desenho } \\
\text { Trabalhos de Agulha e } \\
\text { Economia Doméstica } \\
\text { Trabalhos Manuais } \\
\text { Música } \\
\text { Ginástica }\end{array}$ \\
\hline
\end{tabular}

Fonte: Autora. 
Para o curso especial, destinado à formação específica do professor, o currículo foi composto da seguinte forma:

\section{Quadro 2 - Currículo da Escola Normal - curso especial}

\begin{tabular}{|c|c|}
\hline $1^{\circ}$ Ano & $2^{\circ}$ Ano \\
\hline $\begin{array}{l}\text { Pedagogia } \\
\text { Biologia aplicada à Educação } \\
\text { Metodologia Geral } \\
\text { Metodologia Especial, prática da organização e } \\
\text { administração escolar e Crítica Pedagógica. }\end{array}$ & $\begin{array}{l}\text { Biologia aplicada à Educação Primária } \\
\text { Puericultura } \\
\text { Metodologia Especial, prática da organização e } \\
\text { administração escolar e Crítica Pedagógica. }\end{array}$ \\
\hline
\end{tabular}

\section{Fonte: Autora.}

Segundo o Decreto no 459/1933, que instituiu esse desdobramento, o diretor da Escola Normal ficou responsável pelas aulas de Metodologia Especial e Prática do Ensino, auxiliado pelo professor de Psicologia e Pedagogia, pela diretora da Escola de Aplicação e pela professora auxiliar da cadeira de Psicologia e Pedagogia. A função do diretor se constituiu como parte integrante da consolidação da estrutura hierárquica e burocrática do ensino brasileiro. Frisa-se que, neste período, a sua função diretiva construiu-se a partir dos pressupostos centralizadores baseados na administração científica de empresas.

Ainda de acordo com o Decreto, em seu artigo 15, as Escolas Normais deveriam:

10 - Congregar professores visando o aperfeiçoamento contínuo do magistério;

$2^{\circ}$ - Constituir-se em centro de cultura e investigação psicopedagógica;

$3^{0}$ - Promover a vulgarização da ciência pedagógica;

40 - Aproximar-se tanto quanto possível, no estado da ciência pedagógica, de Metodologia e prática do ensino, à aplicação do método "Centro de Interesses", com ideais associadas (sic), segundo a Escola Decrolí;

50 - Organizar a prática do ensino, através das três fases seguintes:

a) observação em classes-modelo;

b) participação na regência das classes;

c) regência efetiva de classe (PARANÁ, 1933). 
A Escola Normal também deveria criar "[...] centros de cultura pedagógica e literária, [...] organizar salas-ambiente para o ensino especial" de cada disciplina do curso geral e do curso especial. (PARANÁ, 1993).

A reforma empreendida nas Escolas Normais do Estado mostrou-se vinculada a um discurso de reconstrução educacional, com bases no Manifesto dos Pioneiros de 1932, o qual pode ser analisado dentro de uma política de mudanças instituídas pelo Governo do país.

\section{Considerações}

A formação de professores esteve vinculada aos interesses da classe dirigente, porém o professor tornou-se, então, mediador entre o conhecimento e o aluno, procurando possibilitar o acesso aos conteúdos necessários, para que, assim, ocorra o questionamento das relações de dominação. Por conseguinte, a Escola Normal, inserida na sociedade capitalista, foi utilizada como instrumento para legitimar os interesses dominantes. $\mathrm{E}$ isso aconteceu, mais especificamente, pela atuação do diretor na defesa do ideário nacionalista que deveria ser transmitido aos alunos pelas instituições de ensino.

Com a promulgação da República e posteriormente, a Constituição em 1891, inspirada na doutrina liberal, os governantes procuraram organizar o novo regime político e, neste período de reorganização política, acentuou-se o desenvolvimento e a estruturação das ideias nacionalistas. Estabelecido o novo regime, caberia à educação proporcionar a solidez necessária para que se consolidasse a base da nacionalidade. Segundo Nagle (1974, p. 231), o nacionalismo "[...] esteve associado a uma intensa preocupação com a educação, em primeiro lugar, e com a escolarização, em segundo lugar, que se transformam em instrumento para dar solidez às bases da nacionalidade".

A Escola Normal teve sua trajetória marcada por leis e decretos, mas conseguiu manter-se como instituição formadora do 
professor. A partir do momento de sua criação, outras foram sendo criadas, acentuando-se seu crescimento no período republicano. Essas escolas surgiram no momento em que o país passava por uma transição política e a difusão dos ideais liberais os quais ressaltavam a educação como instrumento de consolidação do novo regime e manutenção da ordem social. Porém, sendo elas de competência dos estados, faltava-Ihes ainda organização e, principalmente, as diretrizes estabelecidas pelo Governo Federal. Essa situação perdurou até o advento da Lei Orgânica do Ensino Normal, que centralizou as diretrizes, mas consagrou a descentralização administrativa do ensino e fixou normas para implantação desta modalidade de ensino em todo o território nacional.

No que se refere à Escola Normal de Ponta Grossa, pondera-se que nas primeiras décadas do século $X X$, a instrução pública paranaense renovou-se por meio das reformas implementadas por César Prieto Martinez, delineando-se novos contornos para a estrutura administrativa e pedagógica. Encaminhou-se, neste período, uma busca pelo espaço físico e pela identidade da Escola Normal. A separação do Ginásio e a delimitação de um currículo próprio contribuíram para a efetivação de um curso voltado para a formação sistemática de professores. No espaço administrativo da escola, a legislação educacional enfatizou a definição do papel do diretor escolar, enquanto representante legal do Estado.

Tanto no Paraná quanto nos demais estados, o curso foi alvo de outras reformulações curriculares, todavia, as mesmas não trouxeram avanços significativos em relação às concepções de educação. Consequentemente, a formação de docentes foi mantida numa linha tradicional. $O$ ingresso da mulher no magistério e o processo de constituição da profissão docente aconteceram paralelamente aos momentos de crise e extinção por que passaram as escolas normais, porém tal acontecimento não significou que o Estado desmerecesse a formação docente. Na verdade, 
aconteceu um redirecionamento de prioridades no período republicano, quando a preocupação maior destinou-se pela fiscalização do trabalho do professor.

\section{Referências}

AZEVEDO, F. de et al. Manifesto dos Pioneiros da Educação Nova: a reconstrução educacional do Brasil: ao povo e ao governo. Rio de Janeiro: [s.n.], 1932.

BRUSCHINI, C.; AMADO, T. Estudos sobre mulher e educação: algumas questões sobre o magistério. Cadernos de Pesquisa, São Paulo, n. 64, p. 423, fev. 1988.

CAMPOS, M. C. S. S. Formação do magistério em São Paulo: do império a 1930. Cadernos de Pesquisa, São Paulo, n. 72, p. 5-16, fev. 1990.

FRESSATO, S. T. Pela catolicização da elite curitibana: o projeto intelectual do círculo de estudos "Bandeirantes" - CEB (1929-1945). 2003. 96 f. Dissertação (Mestrado em História) - Universidade Federal do Paraná, Curitiba, 2003.

FUSARI, J. C.; CORTESE, M. P. Formação de professores a nível de $2^{\circ}$ grau. Cadernos de Pesquisa, São Paulo, n. 68, p. 70-80, fev. 1989.

KULESZA, W. A. A institucionalização da Escola Normal no Brasil (18701910). Revista Brasileira de Estudos Pedagógicos, Brasília, v. 79, n. 79, p. 63-71, set./dez. 1998.

LUPORINI, T. J. De Escola Normal a Instituto de Educação: a trajetória de uma escola. Ponta Grossa: Imprensa Universitária/UEPG, 1994.

MARTINEZ, Cesar Prieto. Relatório do Inspetor Geral de Ensino, 1920. Curitiba: Typographia da Penitenciária do Estado, 1920. Disponível em: <https://repositorio.ufsc.br/bitstream/handle/123456789/99764/1920_REL AT\%C3\%93RIO\%20DO\%20INSPETOR\%20GERAL\%20DE\%20ENSINO\%20D O\%20ESTADO $\% 20$ DO $\% 20$ PARAN\%C3\%81. pdf? sequence $=1$ \&isAllowed $=y>$. Acesso em: 24 jul. 2017.

MARTINEZ, Cesar Prieto. Relatório do Inspetor Geral de Ensino, 1921. Curitiba: Typographia da Penitenciária do Estado, 1921.

MIGUEL, M. E. B. A formação do professor e a organização social do trabalho. Curitiba: Ed. UFPR, 1997. 
NAGLE, J. Educação e sociedade na Primeira República. São Paulo: EPU, 1974.

PARANÁ. Decreto n 17, de 9 de janeiro de 1917. Aprova o Código do Ensino. Diário Oficial do Estado, Curitiba, 11 jan. 1917.

PARANÁ. Decreto n 135, de 12 de fevereiro de 1924. Aprova o Regulamento das Escolas Normais Primárias. Diário Oficial do Estado do Paraná, Curitiba, 10 mar. 1924.

PARANÁ. Decreto no 459, de 16 de fevereiro de 1933. Desdobra o plano de estudos das Escolas Normais em Curso Geral e Especial. Curitiba: Departamento Estadual de Arquivo Público, 1933.

PARANÁ. Mensagem do Governador do Estado: Congresso Legislativo do Paraná, 4 out. 1892. Curityba: Typographia d'A República, 1892. Disponível em:

<http://www.arquivopublico.pr.gov.br/arquivos/File/pdf/msg1892_p.pdf>. Acesso em: 15 out. 2003.

PARANÁ. Mensagem do Presidente do Estado: Congresso Legislativo do Paraná, 1 fev. 1920. Curityba: [s.n.], 1920. Disponível em:

<http://www.arquivopublico.pr.gov.br/arquivos/File/pdf/msg1920_p.pdf>. Acesso em: 24 jul. 2017.

PARANÁ. Relatório da Secretaria Geral do Estado do Paraná. Curitiba: Typographia da Penitenciária do Estado, 1925-1926.

RIBEIRO, M. L. S. História da educação brasileira. São Paulo: Moraes, 1986.

VILLELA, H. de O. S. A primeira Escola Normal do Brasil: uma contribuição à história da formação de professores. 1990. 125 f. Dissertação (Mestrado em Educação) - Universidade Federal Fluminense, Niterói, 1990.

VILLELA, H. de O. S. O mestre-escola e a professora. In: LOPES, E. M. T.; FARIA FILHO, L. M.; VEIGA, C. G. (Org.). 500 anos de educação no Brasil. Belo Horizonte: Autêntica, 2000. p. 95-134.

Recebido em 05 de agosto de 2017 Aprovado em 19 de abril de 2018 